\title{
Cerebral blood flow after carotid occlusion and extracranial-intracranial bypass
}

\author{
MYFANWY THOMAS, MICHAEL HENNERICI, JOHN MARSHALL \\ From the Institute of Neurology, National Hospitals for Nervous Diseases, Queen Square, London UK
}

SUMMARY Eleven patients with occlusion of one internal carotid artery showed marked reduction of regional cerebral blood flow (rCBF) through the hemisphere on the affected side with high rCBF on the opposite side. Six of the patients had no surgery, during follow-up of 2 to 5 years. rCBF increased on both sides leaving a persisting asymmetry of rCBF. Five patients had extracranial-intracranial bypass; rCBF increased on the affected side but not on the opposite side. Asymmetry of $\mathrm{rCBF}$ between the hemispheres remained but was much less than in the non-operated group.

In the spectrum of cerebrovascular disease, occlusion of the internal carotid artery is of special interest. It tends to occur in younger age groups and is amenable to surgical procedures. For these reasons accurate information about the natural history is essential. In particular the development of extracranial-intracranial anastomosis of arteries (EC/IC bypass) makes knowledge about cerebral blood flow (CBF) after occlusion and after surgery important.

Halsey et $\mathrm{l}^{1}$, presenting a mixed group of internal carotid and middle cerebral artery occlusions and stenoses in which superficial temporal artery to middle cerebral artery bypass increased blood flow to both hemispheres, though the operated side always remained lower, argued that the asymmetry was the result of reduced metabolic demand on the operated side rather than limited vascular capacity. They considered the bypass increased the vascular reserve. De Weerd et $a l^{2}$ reporting in terms of clinical categories of reversible ischaemic neurological deficit and completed strokes rather than vascular lesions, described an increase in CBF in five after superficial temporal artery to middle cerebral artery bypass and a decrease in five but always with a persisting asymmetry between the hemispheres. Meyer et $\mathrm{al}^{3}$ with a mixed group both as to type of vascular lesion and clinical categories found an increase in CBF to both hemispheres, the increase being greater on the operated side. Yonekura $e^{2 t} \mathrm{al}^{4}$ in a large

Address for reprint requests: Prof J Marshall, The National Hospital for Nervous Diseases, Queen Sq, London WC1N 3BG, UK.

Received 7 July 1983. Accepted 2 August 1983 series of 107 patients with transient ischaemic attacks and strokes found a persisting asymmetry of about $5 \%$ in rCBF between the hemispheres following superficial temporal artery to middle cerebral artery bypass but gave no data about unoperated cases.

Assessment of the effect of superficial temporal artery to middle cerebral artery bypass on CBF is extremely difficult. If the initial event for which surgery is undertaken was a reversible ischaemic neurological deficit or completed stroke, the post operative $\mathrm{CBF}$ may reflect reduced metabolic demand rather than limited vascular capacity. Likewise if $\mathrm{CBF}$ is measured a long time after surgery the result may be affected by the development of new vascular lesions. The present study was undertaken to provide more information in this difficult field.

\section{Methods}

Cerebral blood flow was measured by the intravenous ${ }^{133}$ Xenon clearance technique. ${ }^{5} 7-9 \mathrm{mCi}$ of ${ }^{133} \mathrm{Xenon}$ in $5 \mathrm{ml}$ of normal saline was injected into a vein in the antecubital fossa. The clearance of isotope from the skull was monitored by six external detectors each consisting of a sodium iodide crystal $22 \mathrm{~mm}$ in diameter and $3 \mathrm{~mm}$ thick, connected to a photomultiplier and a dynode chain applied to the scalp. The exhaled ${ }^{133}$ Xenon was monitored by a seventh detector and ducted from the room.

The six cerebral clearance curves and the exhaled ${ }^{133}$ Xenon curve were displayed and the upper envelope of the exhaled ${ }^{133}$ Xenon was plotted. This is equivalent to end-tidal ${ }^{133} \mathrm{Xenon}$ and therefore 
approximates to the arterial ${ }^{133}$ Xenon content in patients with normal lungs.) The data were subjected to two-compartmental analysis by a Varian73 computer using Obrist's formula. ${ }^{6}$

Doppler examination was carried out with a directional C-W doppler device (Débimetre Ultrasonique Directionel Delande) as developed by Planiol, Pourcelot, Pottier and Degiovanni.' A nonfocussed beam at a frequency of $4 \mathrm{mHz}$ was used and the flow profile of the supratrochlear, the vertebral, the subclavian and the carotid arteries in the neck was recorded.

Blood pressure was measured by a standard sphygmomanometer cuff. Blood was obtained for measurement of packed cell volume by venepuncture of a large antecubital vein without stasis. The estimation was by a microhaematocrit method spinning at $12000 \mathrm{~g}$ for five minutes.

\section{Results}

The cases studied were drawn from a group of 46 patients who had carotid occlusion proved by angiography between 1970 and 1982 . Six were known to have died (two from myocardial infarction, one from bacterial endocarditis and three of unknown cause). One patient had developed motor neuron disease and one a stroke after endarterectomy; they, together with 12 who were old and infirm, were too disabled to attend for examination; four patients had moved away. The remaining 22 patients, who clearly had done better than average, were re-examined. Of these, eleven had occlusion of the right carotid artery and had had the CBF measured at the onset; it is with this sub-group that the present report is mainly concerned. There were 10 men and one woman, their mean age being 52.7 years (range 42-67). Nine had presented with transient ischaemic attacks, one with a progressive stroke and one with a mild completed stroke. They were reexamined 1 to 5 years from the onset during which time they had no further cerebrovascular episodes except for one case who had experienced 2 further transient ischaemic attacks. Five had an extracranialintracranial bypass whereas the other 6 had no surgical intervention (table 1).

\section{MEAN CEREBRAL BLOOD FLOW}

The mean CBF at the time of the occlusion and at follow-up for non-operated and operated groups is presented in table 2. The expected mean CBF in relation to age was calculated from data on 52 normal subjects. ${ }^{4}$ Eight of the 11 had a mean CBF $12 \%$ or more below the expected level, the deficit ranging from 12 to $53 \%$.

Of the six non-operated cases five had mean CBF reduced by $12 \%$ or more at the onset. At follow-up four had improved but in only one of these had the improvement brought him within the expected range. The fifth case had experienced a further reduction in mean CBF.

Only three of the five treated by extracranialintracranial bypass had a low mean CBF initially; in two of the three the mean CBF improved achieving the normal range in 1 .

\section{REGIONAL CEREBRAL BLOOD FLOW}

Measurement of mean CBF alone would have overlooked an important phenomenon revealed by regional cerebral blood flow (rCBF) measurements. This was best demonstrated in the six non-operated patients who had an occlusion of the right internal carotid artery, had presented with transient ischaemic attacks alone, had not been subjected to surgery, had not had further episodes (apart from one with very occasional transient ischaemic attacks) and at follow-up did not show any evidence on

Table 1 Clinical data of 11 cases of carotid occlusion

\begin{tabular}{lllll}
\hline Sex & Age $(y r)$ & Presentation & $\begin{array}{l}\text { Duration of } \\
\text { follow-up (yr) }\end{array}$ & Further events \\
\hline No Surgery & & & & No \\
M & 56 & TIA & 5 & No \\
M & 42 & TIA & 2 & No TIAs \\
M & 42 & TIA & 4 & No \\
M & 54 & TIA & 4 & No \\
M & 44 & TIA & 3 & No \\
Extracranial-intracranial bypass & 51 & & & No \\
M & 67 & TIA & 2 & No \\
M & 62 & Progressive stroke & 1 & No \\
F & 54 & TIA & 1 & No \\
\hline
\end{tabular}

TIA $=$ transient ischaemic attack 
Table 2 Mean CBF ( $\mathrm{ml} / 100 \mathrm{~g} / \mathrm{min})$ in 11 cases of carotid occlusion

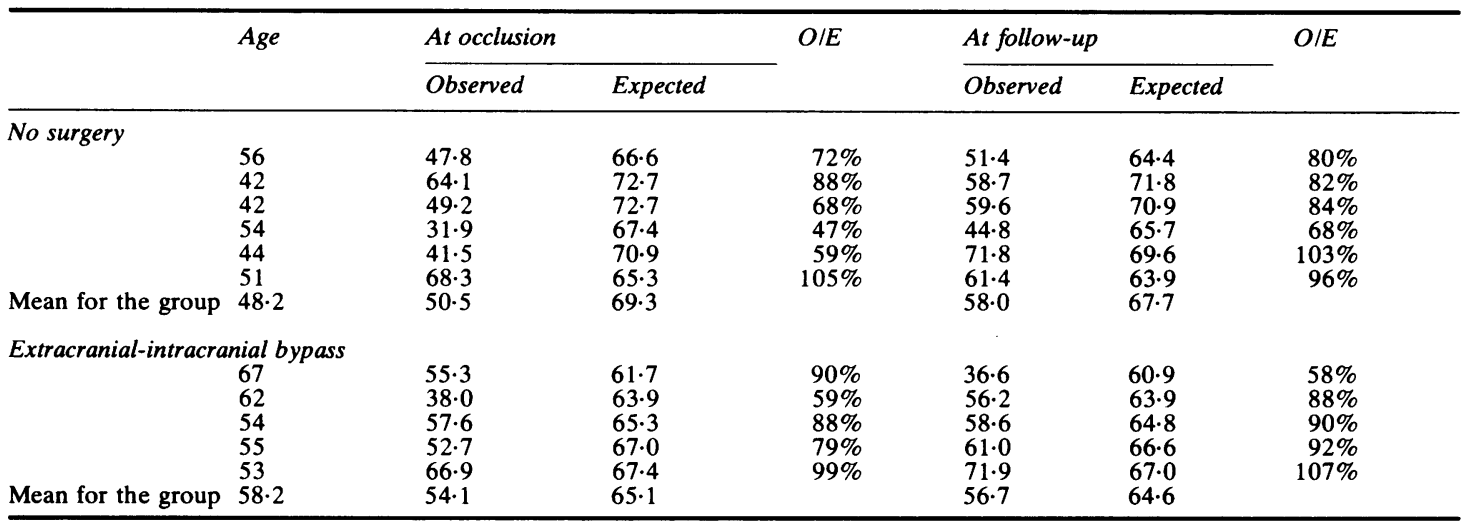

Doppler examination of having developed stenosis or occlusion of other vessels. They therefore provided a group in which the change in CBF following occlusion of one internal carotid artery could be studied without complicating features such as brain damage or new vascular lesions.

rCBF measurement at the time of occlusion showed reduction of flow on the side of the occlusion (fig 1). rCBF was higher on the contralateral

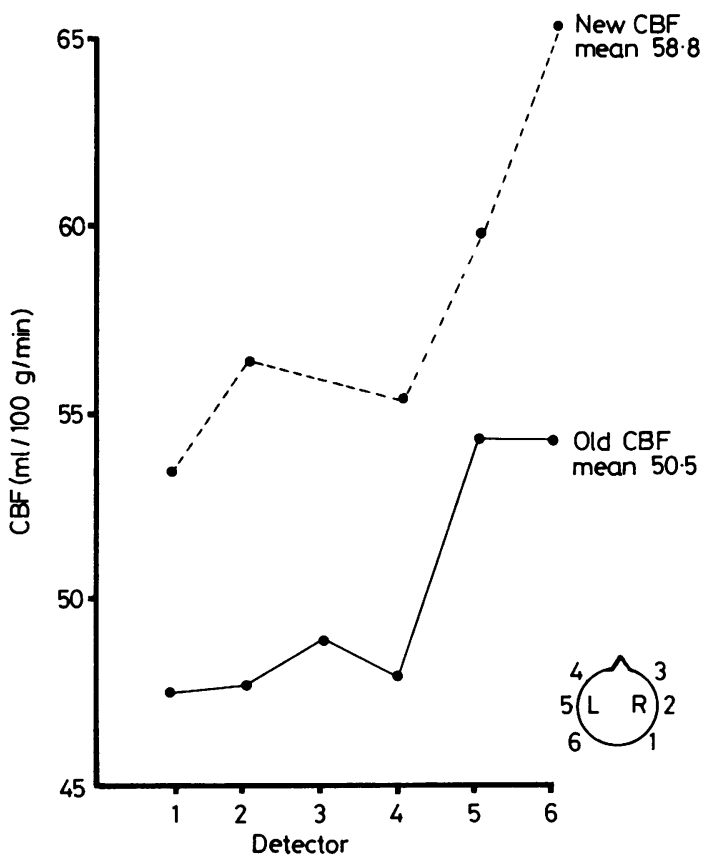

Fig 1 Regional cerebral blood flow ( $\mathrm{ml} / 100 \mathrm{~g} / \mathrm{min}$ ) in 6 non-operated patients with occlusion of the right carotid artery side, the degree of asymmetry being the main determinant of whether the mean CBF was low or remained within the normal range.

Measurement of rCBF at the time of follow-up 2 to 5 years after occlusion showed that even though mean CBF had increased there was persisting asymmetry between the hemispheres (fig 1). The degree of asymmetry from case to case varied but in none was normality completely restored.

The five patients subjected to extracranialintracranial bypass showed at the initial examination the same reduction of $\mathrm{rCBF}$ on the side of the occlusion with higher flow on the contralateral side (fig 2). At the follow-up examination rCBF had increased on the occluded side but there had been little increase on the contralateral side. Doppler examination showed four of the five to have a stenosis of the internal carotid on the latter side. The stenoses were not however of a degree to have haemodynamically significant effects. ${ }^{8}$ It seems the improved mean CBF had been achieved via the extracranial-intracranial anastomosis. Despite this, asymmetry of rCBF between the hemispheres persisted.

DOPPLER EXAMINATION OF EXTRACRANIAL ARTERIAL DISEASE

Doppler examination of the entire group of 22 patients, all of whom had rCBF measured at follow-up, was carried out. Eleven could not be included in the earlier part of this report as they had not had CBF measured at the time of their occlusion.

Bloor's scale ${ }^{9}$ was used to estimate the current extracranial arterial disease score (EAD). This scores five points for occlusion of an internal carotid artery, four points for a $90 \%$ stenosis and $2 \cdot 5$ points for a $50 \%$ stenosis. Absence or occlusion of a ver- 


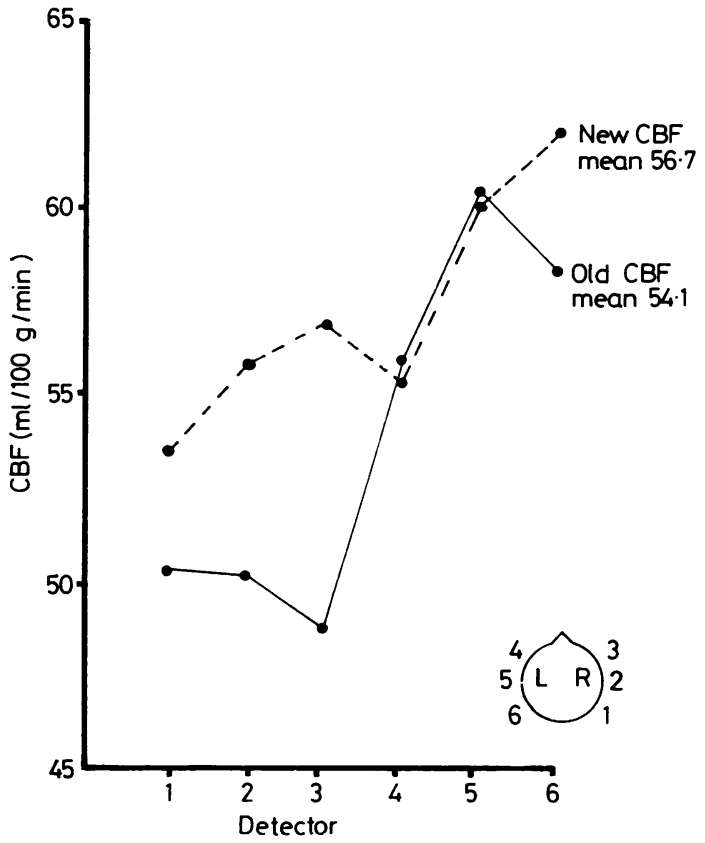

Fig 2 Regional cerebral blood flow ( $\mathrm{ml} / 100 \mathrm{~g} / \mathrm{min}$ ) in 5 Patients with occlusion of the right internal carotid artery treated by extracranial-intracranial bypass

tebral artery is scored at 1.5 points. Each patient was scored according to this scale and their score at their time of review compared with the mean and expected mean $\mathrm{CBF}$. All of the patients with a CBF of $80 \%$ or more of the expected flow had a EAD score of only 5 or 6.5 points, 5 being the minimum possible as all patients in the study had one internal carotid occlusion. Patients with a CBF below $80 \%$ of the expected level had a higher EAD.

Assessment of the development of collateral circulation by Doppler also correlated well with the clinical status of the patient at the time of follow-up (table 3). All three patients in the worst clinical group had evidence of poor collateral circulation compared with two of the eleven patients who had done well.

Table 3 Correlation of clinical status at follow-up and collateral circulation as determined by Doppler examination

\begin{tabular}{|c|c|c|c|c|}
\hline \multirow{2}{*}{$\begin{array}{l}\text { Collateral } \\
\text { circulation }\end{array}$} & \multirow[t]{2}{*}{ Unchanged } & \multicolumn{2}{|c|}{ Clinical status } & \multirow[t]{2}{*}{ Total } \\
\hline & & $\begin{array}{l}\text { Some } \\
\text { impairment }\end{array}$ & Deteriorated & \\
\hline $\begin{array}{l}\text { Good } \\
\text { Poor } \\
\text { Total }\end{array}$ & $\begin{array}{r}9 \\
2 \\
11\end{array}$ & $\begin{array}{l}4 \\
4 \\
8\end{array}$ & $\begin{array}{l}0 \\
3 \\
3\end{array}$ & $\begin{array}{r}13 \\
9 \\
22\end{array}$ \\
\hline
\end{tabular}

\section{Discussion}

The results require little elaboration but their implications are considerable. Following occlusion of the internal carotid artery there was, as expected, a fall in blood flow through the ipsilateral hemisphere. The fall was limited by increased collateral circulation resulting in high flow through the unaffected hemisphere and marked assymetry of hemisphere flow. Mean flow was normal or low depending upon the degree to which the reduction of $\mathrm{rCBF}$ on the ipsilateral side was compensated by the $\mathrm{rCBF}$ on the contralateral side. Subsequently mean CBF tended to improve but asymmetry between the hemispheres persisted.

Although this was in no sense a controlled trial, comparison of the operated and non operated cases is instructive. In the non-operated group rCBF in both the affected and non-affected hemispheres increased by $15 \%$ leaving a persisting asymmetry. Halsey et $a l^{1}$ have argued that this asymmetry may be the result of reduced metabolic demand on the affected side. Whilst this may be a factor in some cases it is unlikely to be operative in the present group. All six had presented with transient ischaemic attacks and at follow up had experienced no further cerebrovascular episodes (apart from 2 trivial transient ischaemic attacks in one subject). Moreover Doppler examination showed no evidence of new vascular lesions. It is therefore very unlikely there had been sufficient parenchymatous damage to reduce metabolic demand in these cases to account for the persisting asymmetry. The asymmetry presumably reflects the need to supply both cerebral hemispheres via one internal carotid artery. Does this involve a degree of "luxury perfusion" of the non-affected hemisphere?

In the group subjected to extracranial-intracranial bypass there was a greater initial asymmetry. Following surgery though the asymmetry was not abolished it was much less, an effect presumably of the extracranial-intracranial bypass. Four of the five cases in this group were shown by Doppler examination at follow-up to have a stenosis on the side opposite to their occlusion. It could be argued that the potential for increase of blood flow was restricted by this. However in view of the evidence that stenosis of the carotid artery has to be very severe before blood flow is reduced ${ }^{10}$ this seems unlikely. It would be desirable to study cases without any contralateral stenosis but unfortunately cases free from other complications such as a severe persisting deficit at the time of or subsequent to the initial occlusion were not forthcoming.

The implications of the results for the role of extracranial-intracranial anastomosis are complex. 
The interval between the initial and follow-up CBF measurement was markedly different between the operated and non-operated patients. This was because extracranial-intracranial anastomosis is a relatively new procedure. Attempts to find contemporary non-operated patients who could be well matched with the operated group proved impossible.

Nevertheless the study indicates that in assessing the outcome of extracranial-intracranial anastomosis measurement of mean $\mathrm{CBF}$ alone is without value. Still less does measurement of blood flow through the anastomosis provide much information. A normal mean CBF can be attained in the presence of low flow through the affected hemisphere if there is high contralateral flow.

The persisting low rCBF must mean a reduction of vascular reserve exposing the hemisphere to increased risk of further ischaemia. If this is to be detected, measurement of CBF must be carried out on a regional basis. This should determine not merely whether rCBF has been increased on the operated side but whether asymmetry in hemisphere flow has been reduced. When combined with $\mathrm{C}-\mathrm{W}$ doppler examination of the extracranial arteries, a complete picture of the haemodynamic status of the cerebral circulation on which to base decisions for or against surgery can be obtained.

Measurement of CBF does not of course provide information about the metabolic state of the brain. High CBF may well be associated with reduced metabolism as in luxury perfusion. The need to determine the role of revascularisation procedures in the treatment of cerebrovascular disease by measurement of cerebral metabolism by positron emission tomography is clear. But in day-to-day management of patients $\mathrm{rCBF}$ measurement and Doppler examination of the extracranial arteries will suffice.

\section{References}

${ }^{1}$ Halsey JH, Morawetz RB, Blauenstein UW. The hemodynamic effect of STA-MCA bypass. Stroke 1982;13:163-7.

${ }^{2}$ De Weerd AW, Veering MM, Mosmans PCM, van Huffelen AC, Tulleken CAF, Jonkman EJ. Effect of the extra-intracranial (STA-MCA) arterial anastomosis on EEG and cerebral blood flow. A controlled study of patients with unilateral ischaemia. Stroke 1982;13:674-9.

${ }^{3}$ Meyer JS, Nakanjima S, Okabe T, et al. Redistribution of cerebral blood flow following STA-MCA by-pass in patients with hemispheric ischaemia. Stroke 1982;13:774-84.

4 Yonekura M, Austin G, Hayward W. Long-term evaluation of cerebral blood flow, transient ischemic attacks, and stroke after STA-MCA anastomosis. Surg Neurol 1982;18:123-30.

5 Thomas DJ, Zilkha E, Redmond S, et al. An intravenous ${ }^{133}$ Xenon clearance technique for measuring cerebral blood flow. J Neurol Sci 1979;40:53-63.

${ }^{6}$ Obrist WD, Thompson HK, Wang HS, Wilkinson WE. Regional cerebral blood flow estimated by ${ }^{133}$ Xenon inhalation. Stroke 1975;6:245-56.

${ }^{7}$ Planiol T. Pourcelot L, Pottier JM, Degiovanni E. Etude de la circulation carotidienne par les méthodes ultrasoniques et la thermographie. Rev Neurol (Paris) 1972;126:127-41.

${ }^{8}$ Hennerici M, Aulich A, Sandmann W, Freund H-J. Incidence of asymptomatic extracranial arterial disease. Stroke 1981;12:750-8.

9 Bloor BM, Asli RP, Nugent GR, Majzoub HS. Relationship of cerebrovascular reactivity to degree of extracranial vascular occlusion. Supplement II of Circulation 1966;33 \& 34:28-34.

${ }^{10}$ Brice JG, Dowsett DJ, Lowe RD. Haemodynamic effects of carotid artery stenosis. $\mathrm{Br} \mathrm{Med} J$ 1964;2:1363-6. 